\title{
A inserção dos direitos humanos nos cursos de engenharia: um novo caminho
}

\section{- La inserción de los derechos humanos en los cursos de ingeniería: un nuevo caminho}

- The insertion of human rights in engineering courses: a new path

\section{Marcos Antônio Silvério \\ Gustavo Pivatto dos Santos ${ }^{2}$ \\ Marcia Maria Fernandes de Oliveira ${ }^{3}$}

Resumo: Este artigo traz uma pesquisa realizada em caráter de projeto piloto, numa Universidade da cidade Curitiba, Estado do Paraná, com o objetivo de compreender, se há necessidade da inclusão de temáticas voltadas ao contexto dos Direitos Humanos, nos cursos de Engenharias. Por meio da abordagem qualitativa, foi realizada a inserção de dois questionários em duas turmas de graduandos, de forma anônima e voluntária, sobre suas impressões e conhecimentos sobre temas voltados aos Direitos Humanos. Autores como Benevides; Amorim; Rego (2018); Sacavino (2009); Dagnino e Novaes (2008), dentre outros, deram sustentação teórica a pesquisa. A partir dos achados, buscou-se a inserção das temáticas nas disciplinas de Tecnologia Social e Economia Solidária. Por fim, acreditamos que a partir desta pesquisa, deve haver

1 Mestre em Educação. Professor da Universidade Tecnológica Federal do Paraná - UTFPR. profmsilverio@gmail.com

2 Mestre em Educação. Psicólogo da Prefeitura Municipal de Princesa/SC. gustavopivattosantos@gmail.com

3 Doutora em Geografia. Professora do Programa de Pós-Graduação do em Educação e Novas Tecnologias do Centro Universitário Internacional - UNINTER. marcia.o@uninter.com 
mais investigações sobre a inserção da temática dos Direitos Humanos em cursos de Engenharias.

Palavras-chave: Direitos humanos. Tecnologia Social. Economia Solidária

Resumen: Este artículo presenta una investigación realizada como proyecto piloto, en una Universidad de la ciudad de Curitiba, Estado de Paraná, con el fin de comprender si es necesario incluir temas relacionados con el contexto de los Derechos Humanos en los cursos de Ingeniería. A través del enfoque cualitativo, se insertaron dos cuestionarios en dos grupos de pregrado, de forma anónima y voluntaria, sobre sus impresiones y conocimientos sobre temas relacionados con los Derechos Humanos. Autores como Benevides; Amorim; Rego (2018); Sacavino (2009); Dagnino y Novaes (2008), entre otros, dieron soporte teórico a la investigación. A partir de los hallazgos, buscamos insertar los temas en las disciplinas de Tecnología Social y Economía Solidaria. Finalmente, creemos que a partir de esta investigación, deberían realizarse más investigaciones sobre la inserción del tema de Derechos Humanos en los cursos de Ingeniería.

Palabras clave: Derechos humanos. Tecnología social. Economía Solidaria

\begin{abstract}
This article presents a research carried out as a pilot project, at a University in the city of Curitiba, State of Paraná, in order to understand if there is a need to include themes related to the context of Human Rights in Engineering courses. Through a qualitative approach, two questionnaires were inserted in two groups of undergraduates, anonymously and voluntarily, about their impressions and knowledge about topics related to Human Rights. Authors such as Benevides; Amorim; Rego (2018); Sacavino (2009); Dagnino and Novaes (2008), among others, gave theoretical support to the research. Based on the findings, we sought to include the themes in the subjects of Social Technology and Solidarity Economy. Finally, we believe that based on this research, there should be more investigations on the insertion of the theme of Human Rights in Engineering courses.
\end{abstract}

Keywords: Human rights. Social Technology. Solidarity Economy 


\section{Introdução}

Atualmente tem se discutido sobre a inserção dos Direitos Humanos (DH) em todas as áreas e níveis da educação. Segundo Oliveira, Santos e Nalepa (2020), os $\mathrm{DH}$ - aqui compreendidos como um produto do processo histórico construído pelos seres humanos, muito antes de ser regulamentado por artigos ou normas - têm a finalidade de garantir a humanização dos indivíduos.

Diante disto, pensando nos currículos dos cursos de educação superior, esta pesquisa - em caráter de projeto piloto - foi desenvolvida em uma universidade no estado do Paraná, Sul do Brasil, em duas turmas de cursos de Engenharias. Foram aplicados questionários a estudantes de uma disciplina voltada a tópicos especiais de ciências humanas, e teve como foco averiguar sobre a inclusão de temáticas de DH nas disciplinas de Tecnologia Social (TS) e Economia Solidária (ES).

A pesquisa teve como objetivo, pensar a necessidade de ampliação e melhoria dos currículos dos cursos de engenharia, com uma maior inserção das temáticas relacionadas aos $\mathrm{DH}$, possibilitando assim aos futuros engenheiros, novos saberes fomentadores do desenvolvimento social.

Segundo Benevides, Amorim e Rego (2018), não se pode negligenciar o fato de que a inclusão dos $\mathrm{DH}$ no cotidiano das universidades é fundamental para o seu fortalecimento de sua dimensão social. É necessário que os educadores se apropriem das discussões sobre os $\mathrm{DH}$, em suas formações, para que, empoderados pelo debate, possam levar tais reflexões às suas práticas pedagógicas. Pressupor a competência docente para a inclusão dos $\mathrm{DH}$ em suas práticas pedagógicas na Educação Básica é sugerir que estes profissionais passem por uma formação docente específica. Nesse sentido, a formação docente inicial e continuada é peça primordial na política de Educação em Direitos Humanos (EDH), uma vez que estes agentes se tornam multiplicadores de valores e princípios dos direitos de homens e mulheres, repetidamente, em seus cotidianos e espaços de trabalho.

\section{Fundamentação}

Documento imprescindível, a Declaração Universal dos Direitos Humanos (DUDH), da Organização das Nações Unidas, proclamada pela Assembleia Geral das Nações Unidas, em 10 de dezembro de 1948, estabelece a proteção universal dos $\mathrm{DH}$ como uma norma comum a ser alcançada por todos os povos e nações. É composta por 30 artigos e contempla no artigo 26 o direito à educação, subdividindo-se em três premissas, de igual importância, conforme segue: 
1. Toda pessoa tem direito à educação. A educação deve ser gratuita, pelo menos a correspondente ao ensino elementar fundamental. $O$ ensino elementar é obrigatório. O ensino técnico e profissional deve ser generalizado: 0 acesso aos estudos superiores deve estar aberto a todos em plena igualdade, em função do seu mérito. 2. A educação deve visar à plena expansão da personalidade humana e ao reforço dos direitos do homem e das liberdades fundamentais e deve favorecer a compreensão, a tolerância e a amizade entre todas as nações e todos os grupos raciais ou religiosos, bem como o desenvolvimento das atividades das Nações Unidas para a manutenção da paz. 3. Os pais têm um direito preferencial para escolher o tipo de educação que será dada a seus filhos. (ONU, 2019).

Diante disto, a educação, por si só se institui como um direito humano. Conforme Sacavino (2009) a educação catalisa a possibilidade de conquista da cidadania com vistas à emancipação humana por meio da socialização do conhecimento. A educação é via fundamental para a promoção de outros direitos, haja vista que almeja o pleno desenvolvimento da pessoa humana e da dignidade.

A formação acadêmica das engenharias é voltada, sobretudo para a economia de mercado. Nessa perspectiva, Dagnino e Novaes (2008, p. 98) afirmam que

\begin{abstract}
Os engenheiros internalizam os valores da sociedade de classes, em geral da pequena burguesia, que estão subjacentes ao seu processo de formação e à sua profissão: controle, individualismo, dominação dos trabalhadores, produção voltada (à) reprodução do capital. Além dos valores da classe dominante, os engenheiros recebem nas universidades e posteriormente na fábrica os conhecimentos "técnicos", e as capacidades e habilidades gerenciais necessários para a reprodução do capital.
\end{abstract}

Atualmente percebe-se a necessidade de uma nova perspectiva no campo da inovação tecnológica na área de ciências sociais, segundo Rodrigues e Barbieri (2008 p. 1070), "Um dos conceitos de tecnologia social atualmente em voga é o que compreende produtos, técnicas ou metodologias replicáveis, desenvolvidas na interação com a comunidade e que representem efetivas soluções de transformação social." Nota-se que o aprimoramento e adaptação destes profissionais podem ser direcionados para uma nova área de atuação nas TS.

Devido às características do profissional das engenharias, e como e onde podem ser desenvolvidas as TS, seria necessária uma formação mais adequada, uma vez que na maioria dos currículos há uma concentração extremamente técnica, em detrimento dos elementos sociais e políticos. Identificando essas variantes, os currículos poderiam adequar e acrescentar áreas do conhecimento que agregariam uma formação acadêmica mais ampla, decorrente das necessidades do conjunto das populações, principalmente as marginalizadas, que são carentes de profissionais com conhecimento tecno-científico. 
Já na disciplina de Economia Solidária (ES), surge uma proposta econômica diferenciada da economia de mercado, tendo seu início no século XIX, porém sua consolidação ocorre no século XX. Explica-se o entendimento da ES, como experiências de atividades de desenvolvimento econômico, envolvendo ações, realizações com objetivos sociais e a construção de ideias de cidadania. Para França Filho (2002, apud Laville, 1999, p. 13), isso implica um processo de "democratização da economia a partir de engajamentos cidadãos". A economia solidária pode ser compreendida como um movimento social que surge a partir das necessidades de inclusão socioeconômica diferenciada de parte da população no processo histórico do capital.

Partindo dessa interpretação, na formação das engenharias e na sua aplicabilidade, poderiam ser aprimorados os saberes e os valores relacionados às temáticas voltadas para os DH. Segundo Benevides (2003, p. 309) a “[...] educação em direitos humanos é essencialmente a formação de uma cultura de respeito à dignidade humana mediante a promoção e vivência dos valores da liberdade, da justiça, da igualdade, da solidariedade, da cooperação, da tolerância e da paz.". Na ES, vários aspectos dos $\mathrm{DH}$, como o desenvolvimento da cidadania, democracia participativa, autogestão, são alguns dos princípios básicos utilizados. Já na TS, a sua efetivação da EDH deveria ocorrer principalmente em áreas em que o capital não atua de forma satisfatória e inclusiva, sendo necessária a fomentação dessa prática pedagógica, pois os empreendimentos tecnológicos geram inserção social e desenvolvem melhorias socioeconômicas e de infraestrutura tanto em áreas urbanas como rurais.

O conhecimento tecno-científico das engenharias na aplicabilidade da TS corresponde a um potencial significativo para superar o subdesenvolvimento, a dependência e a desigualdade nas porções mais necessitadas do Brasil. Por esta premissa, as engenharias teriam como desafio conceber conhecimentos e práticas para a produção de bens e serviços aplicáveis em comunidades carentes, desde que ocorra de forma concomitante aos interesses coletivos das mesmas, levando em consideração os princípios econômicos solidários, como a democracia participativa e ação auto gestionária, entre outros.

Seguindo esse raciocínio, a disciplina de TS e ES se inserem de forma subjetiva nos conhecimentos que contemplam o Plano Nacional de Educação em Direitos Humanos (PNEDH), que é uma política pública educacional fundada nos princípios da democracia, da cidadania e da justiça social. É um instrumento de construção de uma cultura de $\mathrm{DH}$, que busca a efetivação da solidariedade e do respeito às diversidades. O PNEDH conta com cinco eixos de atuação tendo dentre eles o da educação superior (BRASIL, 2018, p. 10). As instituições de educação superior devem ser protagonistas da disseminação e da efetivação de uma sociedade que aceite e promova a inclusão das 
diversidades como expõe o PNEDH:

A conquista do Estado Democrático delineou, para as Instituições de Ensino Superior (IES), a urgência em participar da construção de uma cultura de promoção, proteção, defesa e reparação dos direitos humanos, por meio de ações interdisciplinares, com formas diferentes de relacionar as múltiplas áreas do conhecimento humano com seus saberes e práticas. Nesse contexto, inúmeras iniciativas foram realizadas no Brasil, introduzindo a temática dos direitos humanos nas atividades do ensino de graduação e pós-graduação, pesquisa e extensão, além de iniciativas de caráter cultural (BRAŚIL, 2018, p. 23).

Ainda, segundo o referido documento, faz-se necessário a efetivação dessas mudanças dentro do atual contexto social no qual reinam a desigualdade, a exclusão social, problemas ambientais e o aumento da violência, que ameaçam a efetivação dos DH. Dessa forma, as IES devem desenvolver junto aos seus docentes e discentes a capacidade crítica e emancipadora para enfrentar os problemas supracitados (BRASIL, 2018).

O PNEDH destaca ainda que os estudos em DH podem ser incluídos das seguintes maneiras:

No ensino, a educação em direitos humanos pode ser incluída por meio de diferentes modalidades, tais como, disciplinas obrigatórias e optativas, linhas de pesquisa e áreas de concentração, transversalização no projeto político-pedagógico, entre outros (BRASIL, 2018, p. 24).

A partir da análise observada na pesquisa e aplicação das práticas que contribuiriam para o desenvolvimento das TS e ES, a melhor formação e qualificação dos engenheiros, de acordo com Dagnino (2014), supriria as demandas sociais, promovendo a inclusão social, por meio da criação, construção e adaptação de novas tecnologias que viessem a beneficiar as camadas menos abastadas da população. Mas isso atualmente não ocorre, pois o que se vê na sociedade atual é a utilização maciça das Tecnologias Convencionais (TC) que muitas vezes acabam por desrespeitar questões diretamente ligadas aos $\mathrm{DH}$.

\section{Metodologia}

Nesta pesquisa, em caráter de projeto piloto, utilizou-se a análise qualitativa dos dados levantados em duas turmas de graduandos de uma disciplina com tópicos especiais em ciências humanas. No transcorrer da disciplina foram aplicados dois questionários em cada uma das turmas, de forma anônima e voluntária, sobre suas impressões, conhecimentos e aplicações em uma realidade voltada para os $\mathrm{DH}$.

Abaixo seguem os questionários: 


\section{Primeiro questionário:}

1. Você tem conhecimento sobre outras atividades que não sejam das tecnologias convencionais?

2. Já ouviu falar ou leu sobre Tecnologia Social?

3. Já ouvir falar ou leu sobre Economia Solidária?

4.É possível trabalhar Tecnologia Social aplicado dentro dos Direitos Humanos?

\section{Segundo questionário:}

5. A disciplina de Tecnologia Social pode abordar temas voltados aos Direitos Humanos, bem como suas aplicações?

6. O curso de engenharia que você faz, contempla conhecimentos e aplicações sobre Direitos Humanos?

7. Você acha válida a aplicação da temática dos Direitos Humanos nas disciplinas: Tecnologia Social e Economia Solidária?

\section{Os achados}

Na primeira parte da pesquisa, o professor em sala, constatou a falta de conhecimento sobre as tecnologias não convencionais e também sobre a TS, conforme (gráfico 01), quanto à construção do saber dos $\mathrm{DH}$ e disciplinas correlatas.

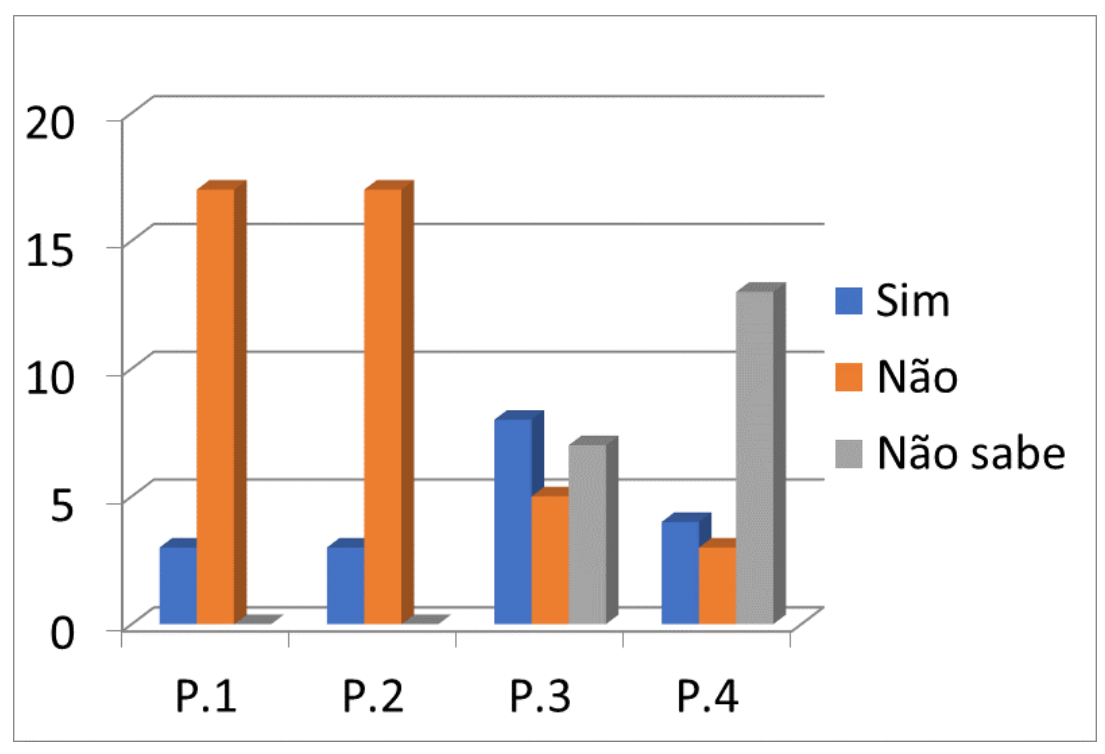

Gustavo Pivatto dos Santos (org.)

A primeira e a segunda pergunta denotam a falta de conhecimento 
da existência de outra tecnologia, que não seja a TC, constata-se que a TS seria uma novidade para os acadêmicos das engenharias. Na terceira pergunta sobre ES ocorre um equilíbrio nas respostas, constata-se que o número de alunos que conhecem a ES é três vezes maior em relação à TS, estando mais próxima do conhecimento das engenharias. A quarta pergunta reflete as respostas anteriores, se a maioria desconhece a ES e a TS, há coerência das afirmações do predomínio do não saber nas respostas sobre a temática na aplicação dos DH naTS.

A partir desta descoberta, optou-se por desenvolver atividades que desenvolvessem saberes sobre as temáticas e que poderiam ser ampliados no decorrer do processo de ensino-aprendizagem. A partir desta observação, passou-se a inserir temas de direitos humanos nas disciplinas TS e ES. Foram inseridas nos planos de aulas; diretrizes, referências bibliográficas e a execução de pesquisa sobre temáticas que poderiam no decorrer do processo de ensino-aprendizagem aproximar os direitos humanos às engenharias. As atividades propostas nas disciplinas TS e ES apresentaram os conteúdos necessários, segundo análise, decorrente das avaliações estudadas pelos acadêmicos.

O planejamento da disciplina seguiu um raciocínio de que os cursos de engenharia desconhecem, em sua maioria, os saberes e as práticas de TS e ES, como constatado na primeira pesquisa. A proposta teve como uma das metas, desvendar, entender e aplicar a EDH, por meio dos saberes e práticas, nas disciplinas ES e TS. Foram contemplados, temas como: democracia participativa, cooperativismo e ação autogestionária. Para tal aprendizado foram utilizados vídeos e textos. No processo, o acadêmico desenvolveu inicialmente uma síntese dos textos com a complementação de um comentário pessoal sobre o tema abordado. Após a atividade escrita, a turma realizou debate no formato de seminário. Concluída a primeira etapa foi proposto o desenvolvimento de projetos que contemplassem no mínimo um dos Objetivos para o Desenvolvimento Sustentável (ODS), tendo como primícia os princípios e os saberes da TS e ES. As atividades desenvolvidas revelaram segundo a pesquisa indicada abaixo no gráfico, que a EDH com os novos saberes adquiridos nos temas de TS e ES contribuem para a formação dos futuros engenheiros com um viés voltado para as práticas dos $\mathrm{DH}$.

Nesse contexto de ensino superior dentro das engenharias se faz necessário um plano para a execução da EDH. Portanto, a formação em EDH significa criar, influenciar, compartilhar e consolidar mentalidades, costumes, atitudes, hábitos e comportamentos e que devem se transformar em práticas cotidianas humanizadoras em nossa sociedade (BENEVIDES, 2003).

A aplicação da EDH realmente efetiva depende da mudança de certos processos formativos; e essa mudança requer uma série de atividades estrutu- 
radas e desenvolvidas, por intermédio das diferentes áreas curriculares. Outro ponto significativo da EDH é se ter clareza dos objetivos que pretendem ser alcançados, sendo eles,

[...] construir estratégias curriculares e pedagógicas coerentes com a visão que assumamos, privilegiando a atividade e participação dos sujeitos envolvidos no processo. Trata-se de educar em Direitos Humanos, isto é, propiciar experiências em que se vivenciem os Direitos Humanos (CANDAU, 2008, p. 6).

Isso significa que a EDH não pode ser compartimentalizada em cada disciplina ou apenas realizada em uma disciplina, mas sim, deve ser um ensino que seja transversal e que as disciplinas tenham uma ligação entre si para um ensino integrado.

Dessa forma, justifica-se a EDH voltada para, a cidadania crítica e participativa e para o respeito à dignidade humana. E que os $\mathrm{DH}$ possam ser compreendidos e respeitados, por meio de uma mudança de cultura, não apenas por uma parcela da população, mas sim pela população como um todo.

Na formação de engenheiros, a substituição das Tecnologias Convencionais pelas Tecnologias Sociais, por meio de uma concepção de Economia Solidária, pode contribuir para ampliar a consciência da igualdade de direitos.

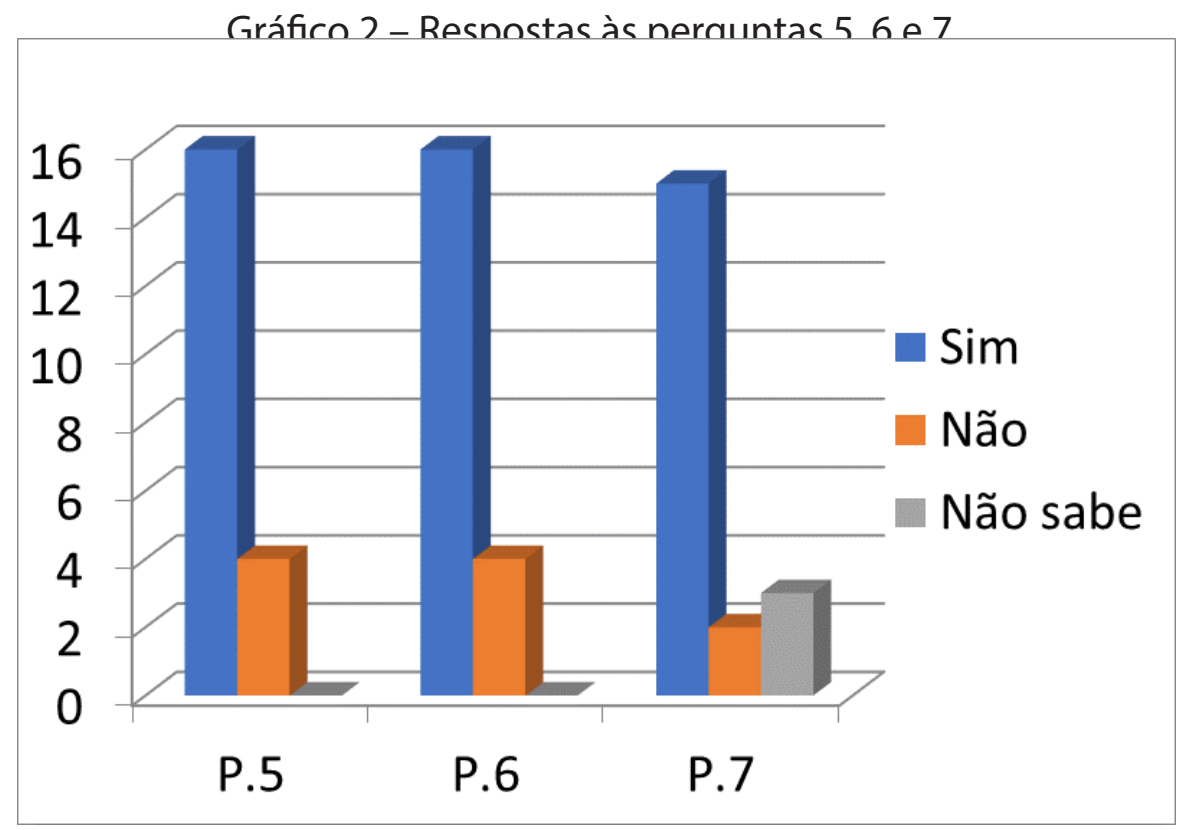


O gráfico 2 explicita claramente a boa aceitação das atividades de EDH nas disciplinas TS e ES.

As atividades realizadas na disciplina de TS, em que o conhecimento tecno-científico denota de forma mais específica às engenharias, enquadrou-se perfeitamente a aplicação dos saberes necessários referentes aos $\mathrm{DH}$ para uma formação mais humanizadora nas engenharias. Assim, as áreas técnicas e de exatas, que compõem grande parte da grade curricular das engenharias, tornam-se direcionadas para o desenvolvimento de soluções de problemas visando uma melhor qualidade de vida da sociedade, para todos sem exceção. Na disciplina de ES a dinâmica da EDH ocorreu de forma mais natural, pois alguns princípios da ES são: autogestão, democracia, solidariedade, prática do comércio justo e solidário, trabalho e renda para o bem viver e não para a acumulação do capital.

As atividades de EDH certamente levaram estes estudantes a refletir sobre o sentido social das engenharias. Um dos aspectos mais importantes dentro da EDH é a educação para o empoderamento das classes sociais empobrecidas, para que dessa forma elas possam também se ver como uma classe com os mesmos direitos e garantias sociais, realizando assim uma mudança histórica para que elas também tenham possibilidade de influenciar nas decisões e processos coletivos dentro de nossa sociedade civil, por meio de uma postura de participação ativa (CANDAU, 2008).

Dessa forma, a Educação em Direitos Humanos, por meio das disciplinas: Tecnologia Social e Economia Solidária, pode contribuir na formação ético-política dos futuros engenheiros.

\section{Considerações finais}

Percebemos, por meio dos achados da pesquisa que há uma falta de compreensão sobre aquilo que os graduandos entendem por TS e ES, assim como o desconhecer sobre os referidos temas que abrangem a EDH. Acreditamos que a partir dessa percepção, uma nova proposta teórico-metodológica possa inserir temas de direitos humanos nos cursos de engenharia.

Partindo dessa interpretação, poderiam ser aprimorados os saberes relacionados aos $\mathrm{DH}$, as disciplinas de TS e ES na formação nos cursos de engenharia, cuja gênese contempla vários aspectos dos $\mathrm{DH}$, como o desenvolvimento da cidadania, democracia, educação, trabalho e renda, entre outros.

Por fim, acreditamos que a partir deste projeto piloto, poderiam ser 
desenvolvidas investigações mais amplas e detalhadas sobre a temática aqui levantada, bem como possíveis análises em projetos curriculares dos cursos de Engenharias.

\section{Referências}

BENEVIDES, Maria Victoria. Educação em direitos humanos: de que se trata? In: LEITE, Raquel Lazzari (org.). Formação de educadores: desafios e perspectivas. São Paulo, SP: UNESP, 2003, p. 309-318

BENEVIDES, Marinina Gruska; AMORIM, de Freitas Rosendo; REGO, Ernny Coelho. Educação em Direitos Humanos: uma análise do currículo e da formação docente nas licenciaturas do Instituto Federal do Ceara. Revista Contexto \& Educação. Fortaleza, v.33, n.104, p. 291 -322, (2018), Disponível em: https://www.revistas.unijui.edu.br/index.php/contextoeducacao/article/ view/6985. Acesso em: 19 ago. 2019.

BRASIL. Plano Nacional de Educação em Direitos Humanos. Brasília: Comitê Nacional de Educação em Direitos Humanos; Ministério dos Direitos Humanos, 2018. Disponível em: https://www.mdh.gov.br/navegue-portemas/educacao-em-direitos-humanos/DIAGRMAOPNEDH.pdf. Acesso em: 13 jun. 2019.

CANDAU, Vera Maria; Educação e Direitos Humanos, Currículo e estratégias pedagógicas. In: ZENAIDE, Maria de Nazaré et al. (org.) Direitos Humanos: capacitação de educadores. João Pessoa: Editora Universitária UFPB, 2008.

DAGNINO, Renato. Tecnologia Social: contribuições conceituais e metodológicas. Eduepb, 2014.

DAGNINO, Renato; NOVAES, Henrique T. O papel do engenheiro na sociedade. Revista tecnologia e sociedade, Curitiba v. 4, n. 6, p. 95-112, 2008. Disponível em: https://www.redalyc.org/pdf/4966/496650325006.pdf. Acesso em: 4 jul. 2019.

FRANÇA FILHO, Genauto Carvalho de. Terceiro setor, economia social, economia solidária e economia popular: traçando fronteiras conceituais. Bahia Análise \& Dados, Salvador, v.12, n. 1, p. 9-19, 2002. Disponível em: http:// cirandas.net/articles/0007/3985/EconomiaSolidria-FronteirasConceituais.pdf. Acesso em: 4 jul. 2019 
NAÇÕES UNIDAS BRASIL. Declaração Universal dos Direitos Humanos. Disponível em: https://brasil.un.org/pt-br/91601-declaracao-universal-dosdireitos-humanos. Acesso em: 30 de junho 2019.

OLIVEIRA, Marcia Maria Fernandes de; SANTOS, Hecilda Aparecida Carneiro; NALEPA, Michelle. Educação em direitos humanos no ensino superior: uma abordagem. EDUCA - Revista Multidisciplinar em Educação, Porto Velho, v, 7, p. 384-394, jan./dez., 2020. DOI: 10.26568/2359-2087.2020.4547. Disponível em: http://www.periodicos.unir.br/index.php/EDUCA/issue/archive. e-ISSN: 23592087

RODRIGUES, Ivete; BARBIERI, José Carlos. A emergência da tecnologia social: revisitando o movimento da tecnologia apropriada como estratégia de desenvolvimento sustentável. 2008. Disponível em: https://bibliotecadigital. fgv.br/dspace/bitstream/handle/10438/21707/S0034-76122008000600003. pdf? sequence=2\&isAllowed=y. Acesso em: 5 jul. 2019.

SACAVINO, Susana. Democracia e educação em direitos humanos na América Latina. Petrópolis. Novamérica, 2009. 